\title{
SOCIO-CULTURAL IMPLICATIONS OF BREAST FEEDING IN URBAN AREA OF PAKISTAN: (A CASE STUDY OF DISTRICT FAISALABAD)
}

\author{
Muhammad Asim ${ }^{1}$--- Shahid Mahmood $^{2}$--- Malik Muhammad Sohail ${ }^{3}$---Farkhanda \\ Anjum $^{4}$--- Farhat Nazir ${ }^{5}$ \\ ${ }^{\prime}$ M. Phil Scholar, Department of Sociology, G. C University Faisalabad, Pakistan \\ ¿Assistant Professor Department of Food Science, G.C University Faisalabad, Pakistan \\ ${ }^{3}$ M. Phil Scholar, Department of Sociology, G.C University Faisalabad, Pakistan \\ ${ }^{4}$ Institute of Agri. Extension and Rural Development, University of Agriculture Faisalabad, Pakistan \\ ${ }^{5}$ Lecturer Sociology, Government College for Women Chiniot, Pakistan
}

\begin{abstract}
Breastfeeding is considered as the most economical and easily accessible complete nutrition for every new born child. Beneficial effects of breast feeding both for the mother and child are well-known. However, there is evidence that breast feeding is on the decline in many developing countries. The main objective of the present study was to explore the different socio-cultural issues which were associated with breast feeding practices. The universe of the present study was Faisalabad District, Pakistan. Multistage sampling technique was applied for the selection of the respondents. At first stage two towns were selected by using simple random sampling technique. At the second stage, four colonies were selected randomly. Convenient sampling was done to select the households. A sample of 120 married women was interviewed who have at least one breast feeding baby from each household. Data show that majority of the mother were in the opinion that breastfeeding is essential for their baby for their physical and mental growth. The researchers also found the main hurdles in the completion period of breastfeeding were poor socio-economic condition of mothers, lack of appropriate gap in birth space, lack of knowledge and awareness among mothers about the benefits of breastfeeding, poor health of mothers, maternal employment and cultural norms of the society. It is suggested that mothers should give proper knowledge and awareness about the benefits of breastfeeding for their child's future survival.
\end{abstract}

Key Words: Breast feeding, Social issues, Cultural and Economic issues, Mother and child health. 


\section{INTRODUCTION}

Breastfeeding has been the natural and normal means of feeding infants. In fact, it is one of the defining characteristic of being a mammal. The importance of breastfeeding before civilization was so pronounced that, wet nurses were contracted for infants of the wealthy and the royal families who were not able to lactate successfully (Wickes, 1953). Human milk is biologically specific for human babies. Breast milk is from living tissue that changes to meet the baby's nutritional needs, and to protect him against disease. The fat content of human milk varies month-to-month, day-to-day, and even hour-to-hour. For example, the milk produced for a premature infant is higher in protein and calories than milk produced for a full-term infant, giving the tiny baby what he needs to catch up on growth. In cold climates, human milk contains more fat and in warm climates, more water (American Academy of Pediatrics, 1997). Hence Breast milk is recognized as the only food that could singly provide all the nutrients required to support optimal growth in the early infancy (Dennison, 2001). Breast-feeding is important not only for the optimal growth and development but has also protective role in decreasing the incidence and severity of infectious diseases including diarrhea, respiratory tract infections, necrotizing enter colitis, urinary tract infection, late onset sepsis reduced rates of sudden infant death syndrome, reduced incidence of diabetes, cancer, It obesity, hypercholesterolemia and asthma, provides analgesia during painful procedures and associated with enhanced cognitive development. There are a number of health benefits to the breastfed child, some of them are significant and others are less significant. Breastfeeding benefits are not only limited to the child, mothers also get benefits from breastfeeding (Rosenblatt \& Thomas, 1995). For full term infants the benefits include i.e. growth and development, greater immune health, higher intelligence, fewer tendencies to develop allergic diseases, hormone release, weight loss, and natural postpartum infertility. Babies who were not breastfed for at least three months have a $27 \%$ increase in the risk of asthma when there is a family history of asthma, compared to children who were breastfed. For children without a family history of asthma and who were not breastfed, there is a $40 \%$ increase in the risk of asthma compared with those who were breastfed. There is an increased risk of overweight and obesity in children, teenagers, and adults who were not breastfed. In mothers who do not have a history of gestational diabetes, each additional year of breastfeeding is associated with a $4-12 \%$ reduction in the risk of developing type II diabetes. There is an increase in breast cancer risk in women who did not breastfeed their infants. The increase in risk may be as much as $28 \%$ as compared to women who breastfed for 12 or more months (Chung et al., 2007). It protects from juvenile onset diabetes (Park, 1992). It is also suggested that breastfed babies are at a significantly reduced risk of gastrointestinal, urinary and respiratory infections (Howie et al., 1990) and that breastfeeding can enhance neurodevelopment (Crawford, 1993). Research also suggests that breastfeeding may protect women from developing breast cancer (Newcomb, 1994) and certain ovarian cancers (Rosenblatt, 1993). The literature also identifies a range of psychosocial advantages for breastfeeding women and babies (Lawrence, 1995). There are numerous studies demonstrating breastfeeding's contribution to saving 
children's lives. Breastfeeding also helps protect infants against acute respiratory illnesses (ARI). A study in Peru showed that infants under 6 months of age who were not breastfed had a fourfold greater risk of developing acute respiratory infections compared with exclusively breastfed babies (Brown et al., 1989). Other developmental benefits of breastfeeding are that, it enhances brain development and learning readiness. Breastfeeding protects babies from illnesses that can cause malnutrition, hearing problems, and learning difficulties (USAID, 2001). Breastfeeding is considered as the most economical and easily accessible complete nutrition for every new born child. Although exclusive breastfeeding is the best way to feed infants but it is not commonly practiced. In Pakistan, the breast feeding initiation rate is about $95 \%$, however prevalence of exclusive breastfeeding is alarmingly low, only $16 \%$ of mothers exclusively breastfeed their children up to 4 months, $31 \%$ complementary feeding, $56 \%$ continued breastfeeding up to 24 month (Ashraf and Jalil, 1990). In Pakistan, lack of knowledge and awareness about feeding infant together with influences of various cultural beliefs and food taboos interfere with the feeding of infants leading to malnutrition with high incidence of infant morbidity and mortality. Pre-lacteal feeding of tea, honey, water and ghutti is a common, deep-rooted tradition for first 2 to 3 days while colostrums is considered thick stale and discarded. Complementary feeding is defective due to ignorance, lack of awareness and influences of baseless beliefs created by family's friends or neighbors. Another misconception of people is that breast feeding helps in transferring different diseases like cancer. But breast cancer is not passed through breast milk. In fact, if a mother has an illness, her breast milk will contain antibodies to it that will help protect her baby from that same illness (Agnew et al. 1997). Sometimes mothers are afraid of transmitted diseases through breast feeding that's why they avoid it (WHO, 2006). Industrialization and rising costs of living is forcing more women to assume working status to earn a living and support their families, there are serious concerns that a working woman has difficulty in meeting home needs. The stress of work causes anxiety and depression among working women resulting in less likeliness to feed their children then the women who are not engaged in such activity outside the house. Prevalence \& duration of breastfeeding has declined in many parts of the world. Decisions relating to infant feeding are highly influenced by social and cultural factors (Dykes and Griffiths, 1998). The use of bottle started initially in the west and soon became a widespread phenomenon globally. Bottlefeeding is now a socially and culturally accepted norm in underdeveloped countries including Pakistan. Mostly mothers belong to upper class of society are less likely to feed their children because it is often not acceptable in their social class or mother don't have much time to feed her/his new born baby (Campbell, 2001). Breastfeeding rates increase with mothers' age. Mothers aged 30 or over had the highest levels of breastfeeding in both 1995 and 2000 (50\% 62\% respectively). However, females aged under 20 demonstrated the lowest breastfeeding incidence (24\%) in both 1995 and 2000 (Infant Feeding Survey, 2000). Research highlights that young women from low income areas are least likely to breastfeed for a number of reasons including embarrassment, lack of role models which portray breastfeeding in positive circumstances, fear of pain, misconceptions that their babies will not gain sufficient 
weight from breastfeeding alone, and exposure to a bottle feeding culture which promotes the use of artificial milk (Shaw et al., 2003).

\section{Justification of the Study}

keeping in view the importance of breast feeding for mother and child health the objective of the present study was to evaluate the breast feeding practices among different social classes; study the effect of mother education and employment on breast feeding practices, and evaluate knowledge of breast feeding among mothers of new born babies.

\section{Materials and Methods}

The study was conducted in urban areas of district Faisalabad. Two Towns Madina Town and Jinnah Town were selected by using multistage sampling technique and sample of 120 respondents was selected by using convenience sampling. The data was collected with the help of interview schedule. A well designed interview schedule consisting of structured and unstructured questions was prepared to explore the research objectives. The average time per interview was about 15 minute and collected data was analyzed by using appropriate statistical technique using the statistical package for social sciences (SPSS). Statistical test chi-square was used to explore the relationship between the variables.

\section{Result and Discussion}

Table 1 illustrates the socio economic and demographic characteristics of participant women of this study. Table shows that 22.5 percent women were from age group of less than 25 years. 27.5 percent were from 25 to 35 years. While a majority i.e. 40.8 percent belonged to age category of 35 to 45 years. Breastfeeding rates increase with mothers' age. Mothers aged 30 or over had the highest levels of breastfeeding (Infant Feeding Survey, 2000). The next section of table 1 indicates that more than half i.e. 59.1 percent women were just housewives while 40.8 percent were engaged in different type of jobs and labors. After that table shows that 10.8 percent women were having just one child, a greater part i.e. 38.3 percent was having 2 to 4 children. 32.5 percent women were with 4 to 6 children. A bulk of respondents i.e. 40.0 percent was having 1 to 5 years school education, 26.6 percent were 6 to 10 years school education and only 15.8 percent were above 11 year of school education, whilst the $17.5 \%$ respondents were illiterate. Table 2 demonstrates that majority of the respondents 76.6 percent breastfeed their children, whilst the 23.3\% respondents don't like to breastfeed their children. Present result strongly confirmed the finding of (Carter, 1996) who found that the powerful link between 'good' mothering and breastfeeding; that is, the desire and ability to feed one's infant 'naturally' is associated with being a good mother. Data show that 7.5 percent of respondents in the viewed that they don't breastfeed their child because of fear of transmission of any disease. A large majority $92.5 \%$ were in the opinion that breastfeed had no any side effects of transmittable diseases. (WHO, 2006) 
repotted that sometimes mothers were afraid of transmitted diseases through breast feeding that's why they avoid it.

Table-1. Socio economic and demographic characteristic of the respondents

\begin{tabular}{lll}
\hline Demographic characteristics & Frequency & Percentage \\
\hline Age & 27 & 22.5 \\
\hline Less than 25 & 33 & 27.5 \\
\hline $25-35$ & 49 & 40.8 \\
\hline $35-45$ & 11 & 9.10 \\
\hline Above 45 & & \\
\hline Professional status & 71 & 59.1 \\
\hline House wife & 49 & 40.8 \\
\hline Job holder & & \\
\hline No. of children & 13 & 10.8 \\
\hline Only 1 & 46 & 38.3 \\
\hline $2-4$ & 39 & 32.5 \\
\hline $4-6$ & 22 & 18.3 \\
\hline Above 6 & & \\
\hline Educational status & 21 & 17.5 \\
\hline Illiterate & 48 & 40.0 \\
\hline 1 to 5 Grade & 32 & 26.6 \\
\hline 6 to 10 Grade & 19 & 15.8 \\
\hline 11 Grade and above & & \\
\hline
\end{tabular}

There are a number of factors that affect women's decisions on how to feed their children (Matusiak, 2005). The provision of tokens for free artificial milk may also act as a disincentive for young and low income mothers to breastfeed their infants (Shaw et al., 2003). 13.3 percent women stated that they don't breastfeed child because commercials of formula milk convince them to be a better nutrition for their child. Formula feeding poses a risk to the notion of 'good mothering'; it carries with it stigma (Goffman, 1963) A considerable majority of mother's i.e.65.8 percent breastfeed child more than 2 times a day. 66.6 percent of mothers stated that breastfeeding their child is absolutely their own decision. Men's support for breastfeeding has been recognized as important in women's decision to either breast or formula feed their infant (Freed and Fraley, 1993; Earle, 2000). 5.83 percent are those who breastfeed due to husband's will. The desire for paternal involvement also appears to be an influential factor; fathers were either seen as able to alleviate the daily grind of early motherhood, or there was a desire for 'shared parenting'. It is ironic that the desire for a more conjugal parenting relationship (Lewis, 1986). A greater part of study participants i.e. 44.1 percent think breastfeeding is bad for their physical beauty. There is a general agreement among anthropologists that the household acts as a context for the child as well as a mediator that provides the support associated with positive child well-being outcomes (Cox et al., 1997). The family of only 14.1 percent mothers appreciates their act of breastfeeding. A slight no. of respondents i.e. 9.16 indicated that they wash their breasts before breastfeeding. A majority of 63.3 percent had decided before delivery that they are going to breastfeed their baby. 
Table-2. Distribution of mothers regarding their perception about breastfeeding

\begin{tabular}{|c|c|c|c|c|}
\hline \multirow[t]{2}{*}{ Attitudinal Statements } & \multicolumn{2}{|l|}{ Yes } & \multicolumn{2}{|l|}{ No } \\
\hline & Frequency & Percentage & Frequency & Percentage \\
\hline Liking to breastfeed your children & 92 & 76.7 & 28 & 23.3 \\
\hline $\begin{array}{l}\text { In your opinion breastfeeding have any side effect i.e. any } \\
\text { transmittable diseases }\end{array}$ & 09 & 7.5 & 111 & 92.5 \\
\hline If not, is it due to commercials of formula milk & 16 & 13.3 & 104 & 86.7 \\
\hline Breastfeed your child more than 2 times a day & 79 & 65.8 & 41 & 34.2 \\
\hline It is Women's personal decision to breastfeed & 80 & 66.7 & 40 & 33.3 \\
\hline It is only woman's husband's will to breastfeed & 07 & 5.8 & 113 & 94.2 \\
\hline Women aware of medical benefits of breast feeding & 41 & 34.2 & 79 & 65.8 \\
\hline Breastfeeding effect your physical beauty & 53 & 44.2 & 67 & 55.8 \\
\hline Family appreciates the act of breastfeeding & 17 & 14.2 & 103 & 85.8 \\
\hline Washes her breasts before feeding their child & 11 & 9.2 & 109 & 90.8 \\
\hline Decided to breastfeed their child before delivery & 76 & 63.3 & 44 & 36.7 \\
\hline It is the child's right to be breastfed & 89 & 74.2 & 31 & 25.8 \\
\hline Mother care about her nutrition during breastfeeding & 61 & 50.8 & 59 & 749.1 \\
\hline
\end{tabular}

74.1 percent mothers consider it's their child's right to be breastfed. 50.8 percent mothers do care about your nutrition during breastfeeding.

\section{CONCLUSION}

The research more or less uncovers issues, which have also been observed in previous studies on breast feeding practices in Pakistan. However this is more effective in identifying specific areas of Faisalabad. Results showed that $50.8 \%$ of respondents had knowledge about breast feeding and those who had not (49.2\%). only (28.3\%) had knowledge about hygiene during breast feeding. A mainstream population $34.2 \%$ had not access to nursing facility at work place; mostly mothers $(87.5 \%)$ used bottle feed during breast feeding period to their children. It is well known that human milk is important not only for the optimal growth and development but has also protective role in decreasing the incidence and severity of infectious diseases. But now a day's breastfeeding is rapidly decline. There are many social, cultural, and economic issues which affect the breast feeding practices. These factors contain different aspects like poor economic condition of mother, lack of appropriate gap in birth space, social class differences, lack of knowledge and awareness among mothers about the benefits of breastfeeding, mothers poor health condition, maternal employment and cultural norms of the society.

\section{Suggestions}

It is suggested that mothers should give proper knowledge and awareness about breastfeeding basic techniques of feeding and the beneficial effect of human milk that they breast feed their children properly with knowing the merits of breast feeding. Fake cultural beliefs about colostrums that it is unhealthy for baby must be demolish and mother should give colostrums to her baby after half an hour right after birth. Nursing facilities should available at working place for breast feeding mothers that they should continue breast feeding to her baby without any hindrance, Mother should take care of her health, take healthy food, take extra minerals and vitamins and regularly visit the doctor that in the case of any health related problem she tackles 
the problem easily. Because if the mother is facing problem of malnutrition or other any illness than how she can proper feed her baby. Family as well as husband should encourage breastfeeding that boosts the confidence of mother.

Funding: This study received no specific financial support.

Competing Interests: The authors declare that they have no competing interests.

Contributors/Acknowledgement: All authors contributed equally to the conception and design of the study.

\section{REFERENCES}

Agmpodi, S.B. (2006).Utilization of private sector for immunization of children in Colombo municipal council area. MSc. Dissertation. Post Graduate institute of Medicine, University of Colombo;.Lucas, A., and T.J. Cole. 1990. Breast milk and neonatal necrotizing enter colitis. Lancet Vol.336, pp.1519-1522.

American Academy of Pediatrics work group on breast feeding. (1997). Breast feeding and the use of human milk. J. Pediatrics. Vol.100, pp.1035-139.

Agnew, T., Gilmore, J. and Sullivan, P. (1997). A Multicultural Perspective of Breastfeeding in Canada. Minister of Public Works and Government Services, Canada.

Ashraf, R. N. F., J. Khan. (1990). Pakistan V. Feeding Pattern. Acta Pediatr, Vol.390, pp.47-61.

Bhat, I.A., G.N. Shah, G.M. Dhar, S. Mehnaz. (1992). A study on the impact of maternal knowledge and practice on the nutritional status of infants. Ind. J. Matern Child Hth3: 12-15.Breastfeeding and Maternal and Infant Health Outcomes in Developed Countries, Structured Abstract. http:// www. ahrq. gov/ clinic/ tp/brfouttp.htm

Brown, K. H., Black, R. E., de Romana, G. L., de Kanashiro, H. C. (1989). Infant-feeding practices and their relationship with diarrheal and other diseases in Huascar (Lima), Peru. Pediatrics Vol.83, No.1, pp.3140 .

Campbell, K., Waters, E. O’Meara. and Summerbell, C. (2001). Interventions for Preventing Obesity in Childhood. A Systematic Review Observation. Vol.2, pp.149-157.

Carter, P. (1996). Breastfeeding and the social construction of heterosexuality, or 'what breasts are really for'. In Holland, J. and Adkins, L. (eds) Sex, Sensibility and the Gendered Body. Macmillan Press, London, pp. 99-119.

Cox, D. N.; Anderson A., Reyholds S., Mela D. J, Lean M. E. J., (1997). Measuring Fruit and Vegetable Intake: Is Five Times a Day Enough? European. Journal of Clinical Nutrition. Vol.51, pp.177-180.

Crawford, M. A. (1993). The role of essential fatty acids in neurodevelopment: implications for prenatal nutrition. American Journal of Clinical Nutrition, Vol.57, pp.7035-7105.

Dennison, BA.; Rockwell, HL.; Nichols, MJ.; (2001). Use of Low-Fat Milk by Children in the New York State. WIC varies with parental characteristics. JAM Diet Assoc., Vol. 464-6

Dykes, F. and Griffiths, H. (1998). Societal influences upon initiation and continuation of breastfeeding. British Journal of Midwifery, Vol.6, pp.76-80.

Earle, S. (2000). Why some women do not breastfeed: formula feeding and fathers' role. Midwifery, Vol.16, pp.323-330. 
Freed, G. L. and Fraley, J. K. (1993). Effect of expectant mothers' feeding plan on prediction of fathers' attitudes regarding breast-feeding. American Journal of Perinatology, Vol.10, pp.300-303.

Goffman, E. (1963). Stigma: Notes on the Management of Spoiled Identity. Prentice Hall, New Jersey.

Howie, P. W., Forsyth, J. S. and Ogston, S. A. et al. (1990). Protective effect of breastfeeding against infection. British Medical Journal, Vol.300, pp.11-16.

Infant Feeding Survey. (2000). Equality and Inequalities in Health and Social Care in Northern Ireland: A Statistical Overview (DHSSPS, 2004:106).

Chung, M., Raman G, Chew P, Magula N, DeVine D, Trikalinos T, Lau J. (2007). Breastfeeding and Maternal and Infant Health Outcomes in Developed Countries. Rockville, M. D. Agency for Healthcare Research and Quality; Evidence Report/Technology Assessment No. 153.

Lawrence, R. (1995). The clinician's role in teaching proper infant feeding techniques. The Journal of Pediatrics, 126 (Suppl. 1), pp.112-117.

Lewis, C. (1986). Becoming a Father. Open University Press, Milton Keynes.

Matusiak, M. M. (2005). A Cultural Perspective of the Feeding Habits. The Internet Journal of Nutrition and Wellness.

Melissa, K.N. (2009). About.com Health's Disease and Condition content is reviewed by the Medical Review Board. http://breastfeeding.about.com/od/breastfeedingbasics/a/momcare.htm.

Newcomb, P. A., Storer, B. E., Longnecker, M. P. et al. (1994). Lactation and a reduced risk of premenopausal breast cancer. The New England Journal of Medicine, Vol.330, pp.81-87.

Park, P. (1992). Cows' milk linked to juvenile diabetes. New Scientist, Vol.22, pp.1835-1839.

Rosenblatt, K. A. (1993). Lactation and the risk of epithelial ovarian cancer.International Journal of Epidemiology, Vol.22, pp.192-197.

Rosenblatt, K. A. \& Thomas, D. B. (1995). Prolonged Lactation and Endometrial Cancer: WHO Collaborative Study of Neoplasia and Steroid Contraceptives. International Journal of Epidemiology, Vol.24, No.3, pp.499-503.

Shaw, R., Wallace, L.M. \& Bansal, M. (2003). "Is Breast Best? Perception of infant feeding”. Community Practitioner, Vol.76, No.8, pp299-303.

United States Agency for International Development (USAID), (2001). Breastfeeding: Background Paper. Washington, DC. December.

Wickes, I.G. (1953). A brief history of infant feeding, Part 1, primitive people's Ancient works Renaissance Writers. Arch Dis. Child. Vol.28, pp.15 1-158.

World Health Organization. (2007). AIDS epidemic update. December 2006. Available at: http://data.unaids.org/pub/EpiReport/2006/2006_EpiUpdate_en.pdf(accessed October 2007). 